\title{
Improved Limiting Criteria for Deflection in Multi-Story Buildings Subjected to Aerodynamic Load
}

\author{
Alkali Abba M., Onundi L.O and Mu'azu Nura \\ (Department of Civil and Water Resources Engineering, University of Maiduguri, Nigeria)
}

\begin{abstract}
In recent times, there have been rapid changes in the Architectural design of multi-story buildings tending towards slenderer structures due purposely to space utilization. These changes are not without some inherent challenges on the serviceability requirements of these buildings; of major concern are deflection, oscillation, and excessive vibration developed by the action of wind on the structural members. This study carried out an evaluation of shear wall and frame network subjected to aerodynamic wind load on a 60m, 20 storeys regular building model for aerodynamic resistance of multi-story building with a view to having further improvement on the serviceability criteria. Wind load assessment was carried out in accordance with recommendations of Euro code using critical wind speed of Maiduguri $(47 \mathrm{~m} / \mathrm{s})$ as primary data. Analysis of the structural system was carried out by using approximate rapid manual method and standard software package. An improved equation was developed for deflection from the result of the analysis which satisfies the limiting criteria of the code. Results obtain from the improved equation when compared with the existing limiting criteria shows more flexural rigidity up to about $95 \%$ of the height of the building. This means that the improved equation will provide less deflection than the existing method up to $95 \%$ of the building, thereby providing more comfort to the occupants of the buildings.
\end{abstract}

Keywords: Shear-walls, Frame network, Aerodynamic, wind load

\section{Introduction}

The world is undergoing rapid changes in the field of creativity and there is no doubt the field of multistorey structures are not left behind. For the purpose of space utilization modern architecture is tilting towards high rise building which require further researches in order to improve on the existing design criteria's so as to accommodate challenges that come with these changes. A multi-storey building must resist the combined effect of horizontal and vertical loads for the stability to be ensured. They resist these loads, through their foundations, shear walls, frame network with their floors slab flexural rigidity. Proper anticipation of wind effects is an important aspect of successful multi storey building design. Wind effects are naturally of dynamic nature since its gust or pulsation is time dependent, whereas the structural loading and response can be considered as static, dynamic or aero-elastic depending on the response characteristics of the structure [1] \& [2].

\section{Stiffness And Drift Limitation}

The provision of adequate lateral stiffness is a major consideration in the design of multi-storey building in wind and seismic zone. High wind pressures on the sides of multi-storey buildings produce base shear and overturning moments. These forces cause horizontal deflection in a multi -storey building. Deflection must be maintained at a sufficiently low level for the proper performance of both structural and non-structural components. Though serviceability is satisfied by drift and foundation condition in the range of $\mathrm{H} / 500$ to $\mathrm{H} / 1000$, therefore, the design criteria are strength, serviceability, stability and human comfort. The strength is satisfied by limit stresses, and stability is satisfied by sufficient factor of safety against buckling and P-Delta effects. The factor of safety is around 1.67 to 1.9 [3] \& [4]. Besides, Lateral stiffness of a building is satisfied by the drift index in the range from 0.001 to 0.005 [5] \& [6]. The need to have good understanding of the nature of wind load and estimation of inter-storey drift of multi-storey buildings susceptibility to oscillation (sway) under lateral wind loading are very important [7] \& [8]. Peak inter-storey drift and lateral displacement are two essential parameters used for assessing the lateral stability and stiffness of lateral force resisting systems of high rise buildings. The efficiency of lateral load resisting system for multi-storey buildings heavily depends on drift limits [9]. From the foregoing it is seen that the design of modern high-rise buildings or structures subjected to the effect of wind loads requires special consideration of the assessment of the flexural rigidity of the structural members. It is however observed in recent times, there have been rapid changes in the Architectural design of multi-storey building due purposely to space utilization. These changes have some challenges on the serviceability requirements of these buildings; of major concern are deflection, oscillation, and excessive vibration developed by the action of wind on the structural members. Therefore, this study evaluate shear wall and frame network subjected to aerodynamic wind load on regular building model for aerodynamic resistance of multi storey building with a view to further improvement in the design criteria to have more comfortable structures. 


\section{Method}

\subsection{Evaluation of the Flexural Rigidity of Structural Members}

The flexural rigidity of structural members is the product of the moment of inertia and the material Modulus of elasticity. The total rigidity is the sum of the quantities separately determined for the shear walls $\mathrm{B}_{s w}^{t}$, columns $\mathrm{B}_{\text {col }}^{t}$ and beams $\mathrm{B}_{\mathrm{b}}^{t}$ as shown in equations ( 1 to 8 ) respectively [10].

2.1 Shear Walls, Columns and Beams

$$
\begin{aligned}
& \mathrm{B}_{\text {sw }}^{\prime}=0.85 E_{c} \mathrm{I}_{s w}\left(\frac{b l_{s w c l}^{3}}{12}+2 A_{c} l_{c c}^{\mathrm{a}}\right) \\
& \mathrm{B}_{\text {col }}^{r}=0.85 E_{c} \mathrm{I}_{\text {col }} \\
& \mathrm{B}_{\mathrm{b}}^{\prime}=0.85 E_{c} \mathrm{I}_{\mathrm{b}} \\
& \mathrm{B}_{\text {sw }}=\sum \mathrm{B}_{\text {sw }}^{\prime} \\
& \mathrm{B}_{\mathrm{col}}=\sum \mathrm{B}_{\mathrm{col}}^{\prime} \\
& \mathrm{B}_{\mathrm{b}}=\sum \mathrm{B}_{\mathrm{b}}^{\prime} \\
& \mathrm{B}_{\phi}=\mathrm{c}_{\phi} \mathrm{I}_{\phi} \\
& \mathrm{k}_{\phi}=\frac{\mathrm{Br}_{\mathrm{sW}}}{\mathrm{H} \mathrm{B}_{\phi}}
\end{aligned}
$$

Where, $\mathrm{b}=$ thickness of the shear wall, $l_{\text {swcl }}=$ Shear wall clear span along the transverse direction Ac $=$ crosssectional area of the column, $l_{c c}=$ Dimension column to column Centre line along the transverse direction, $\mathrm{I}_{\mathrm{sw}}=$ moment of inertia of shear wall, $I_{\text {col }}=$ moment of inertia of the columns, $I_{b}=$ moment of inertia of the beams, $I_{\Phi}$ $=$ moment of inertia of the foundation, $\mathrm{c}_{\Phi}=$ bed function for the foundation, $l_{\phi}=$ Length of a foundation, $b_{\phi}=$ Width of a foundation, and $K_{\phi}=$ Shear wall sub and super structural influence coefficient

2.2 Columns and Beams Linear Stiffness's

Column linear stiffness $\left(i_{\text {col }}\right)$

$$
\mathrm{i}_{\mathrm{col}}=\frac{\mathrm{Bl}_{\mathrm{col}}}{\mathrm{h}}
$$

Beam linear stiffness $\left(i_{b}\right)$

$$
\mathrm{i}_{\mathrm{b}}=\frac{\mathrm{B} r_{\mathrm{b}}}{\mathrm{l}_{\mathrm{ac}}}
$$

Sum of linear stiffness's are given as

$$
\begin{aligned}
& \mathrm{S}=\sum \mathrm{i}_{\mathrm{col}}=\mathrm{n}_{\mathrm{col}} \mathrm{i}_{\mathrm{col}} \\
& \mathrm{r}=\sum \mathrm{i}_{\mathrm{b}}=\mathrm{n}_{\mathrm{b}} \mathrm{i}_{\mathrm{b}}
\end{aligned}
$$

Where

$\mathrm{h}=$ building storey height, $\mathrm{S}=$ sum of columns linear stiffness, $\mathrm{r}=$ sum of beams linear stiffness, $\mathrm{n}_{\text {col }}=$ number of columns [ $\left.\mathrm{n}_{\text {frames }} \times\left(\mathrm{n}_{\text {bays }}+1\right) \times \mathrm{n}_{\text {storey }}\right], \mathrm{n}_{\mathrm{b}}=$ number of beams $\left[\mathrm{n}_{\text {frames }} \times \mathrm{n}_{\text {bays }} \times \mathrm{n}_{\text {storey }}\right]$

2.3 Model Structural Characteristics

When a multi-storey building is disturbed by wind loading, a unit elastic horizontal displacement (i.e. elastic line) produced will cause a horizontal force equal to $\mathrm{F}_{\text {hor }}$ (in $\mathrm{kg}$ or $\mathrm{kN}$ ) given by equation (13):

$\mathrm{F}_{\text {hor }}=\frac{12}{\mathrm{~h}\left(\frac{1}{\mathrm{~s}}+\frac{1}{\mathrm{r}}\right)}$

The linear characteristics of the rigidity, $S_{\mathrm{wc}}$ (in $\mathrm{cm}$ or $\mathrm{m}$ ) of combined shear walls and frame acting as load bearing structural elements are determined using equation (14):

$\mathrm{S}_{\mathrm{wc}}=\sqrt{\frac{\mathrm{B}_{\mathrm{sW}}}{\mathrm{F}_{\mathrm{hor}}}}$

Structural characteristics of rigidity $\lambda$, for the multi-storey building is given by equation (15):

$\lambda=\frac{H}{S_{w c}}$

Therefore, the structure's influence function, $¥$ for only super structure is given by (16):

$¥=\frac{1+\lambda \sinh \lambda}{\cosh \lambda}$

Structural characteristics of rigidity $\alpha_{0}$, for the building foundation is given by equations (17)

$\alpha_{0}=\frac{1+\mathrm{k}_{j} \beta_{1}}{1+\mathrm{k}_{j} \beta_{2}}$

$\beta_{1}=\frac{\lambda \sinh \lambda}{1+\lambda \sinh \lambda}$

$\beta_{2}=\frac{\lambda \operatorname{Sinh} \lambda}{\operatorname{Cosh} \lambda}=\lambda \tanh \lambda$ 
The non-dimensional co-ordinate for these characteristic values is directly proportional to the building height and inversely proportional to the linear characteristics of the rigidity, $S_{\mathrm{wc}}$ (in $\mathrm{cm}$ or $\mathrm{m}$ ) for combined shear walls and columns acting as load bearing structural elements and can be determined using equation (20):

$\varphi=\frac{x}{s_{w c}}=\frac{H}{s_{w c}}=\lambda$

Where;

$\mathrm{x}=$ height of the story level being considered

At the highest point of the multi-storey building, the anticipated maximum horizontal displacement that takes into consideration a simultaneous rotation of the foundation is given by equation (21):

$\mathrm{f}_{\max }=\frac{\mathrm{P}_{\mathrm{n}} \mathrm{H}^{2}}{2 \mathrm{~F}_{\mathrm{hor}}}\left[1-\frac{2 \mathrm{~B}_{\mathrm{sW}}\left(\mathrm{F}_{\mathrm{ag}}-1\right)}{\mathrm{H}^{2} \mathrm{~F}_{\text {hor }}}\right]$

where

$\frac{\mathrm{P}_{\mathrm{n}} \mathrm{H}^{2}}{2 \mathrm{~F}_{\mathrm{hor}}}=$ Is the frame-super structural component of the equation

$\left[1-\frac{2 B_{s W}\left(x, a_{D}-1\right)}{H^{2} F_{h o r}}\right]=$ Is the shear wall substructural component of the equation

But the limiting condition in equation 20 must be satisfied by equation (22):

$\frac{f_{\max }}{H} \leq \frac{1}{500}$

\subsection{Analysis of Multi Story Building}

For the study, a model of $60 \mathrm{~m}$ height, 20 story reinforced concrete frame building with shear walls is considered (Figure 3.2). The wind load is acting on the combined transverse 3 shear wall and 10 networks of frames. The frame has twelve equal bays of $4.6 \mathrm{~m}$ along $\mathrm{X}$ axes and three bays of $4.6 \mathrm{~m}, 3 \mathrm{~m}$ and $4.6 \mathrm{~m}$ along $\mathrm{Y}$ axes respectively. Modulus of elasticity of concrete (Ec) of $31.5 \mathrm{kN} / \mathrm{mm}^{2}$ is to be used for analysis of the reinforced concrete building. To resist the local prevailing wind gust, three vertical transverse shear walls 175 $\mathrm{mm}$ thick were provided. Details of the frame are shown in figure 3.3. The bed constant for the soil is assumed to be $50000 \mathrm{kN} / \mathrm{m}^{3}\left(5000 \mathrm{~T} / \mathrm{m}^{3}\right)$. The distribution of the structural components of the layout are arranged symmetrically to avoid torsional response along both orthogonal directions. The building is to be evaluated for wind action in accordance with EC 1[11] (2005). The proposed building is assumed to be situated on a relatively flat terrain in an open area in Maiduguri, Borno state, Nigeria where it is exposed to winds blowing from all directions. The local prevailing wind speed of $47 \mathrm{~m} / \mathrm{s}$ was used as primary data. The methods involve two stages of analysis. First, Approximate manual analysis of the 2-dimentional structural model. Secondly, ETABS 2015 (Extended 3-dimensional analysis of Building System) software package [12] was used to carry out the full analytical analysis of the 3 -demensional building model based on the equivalent static analysis.

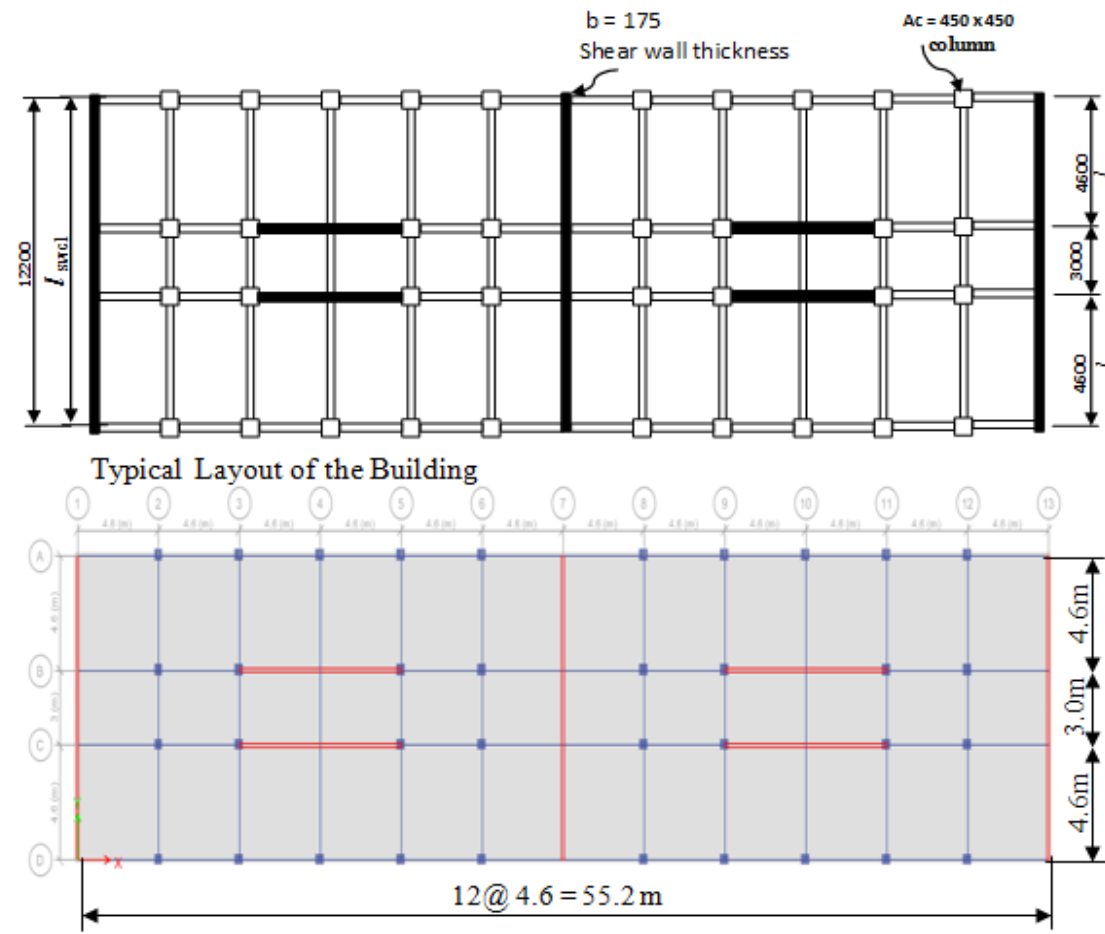

a) Plan

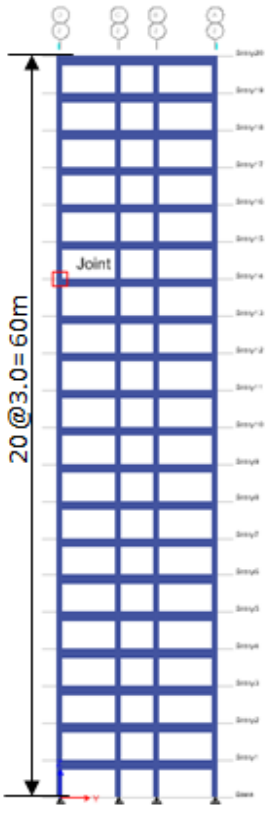

b) Section 


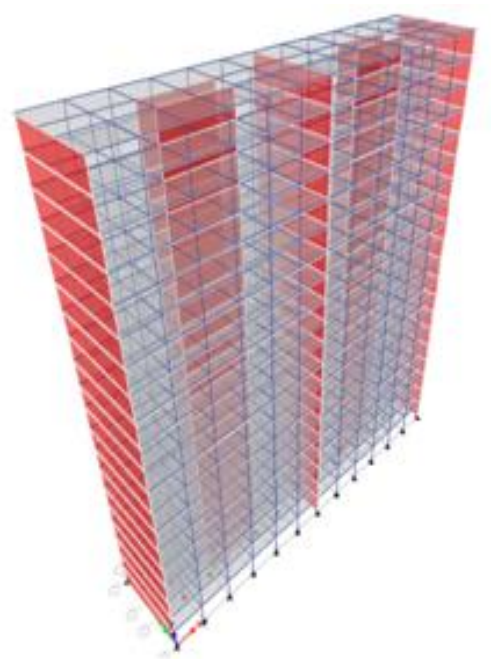

Figure 3.3: A Typical model of the Building

\section{Results}

\subsection{Assessment of the Flexural Rigidity of Structural Members}

The values of the results shown in Table 4.1 indicate that the flexural rigidity of structural members is dependent on the moment of inertia and the material modulus of elasticity and are actually influence by structural member dimension specifically the size of members of the network of frames and shear-walls which play a leading role in contributing to the stiffness of the system. The result illustrates a larger value at the base as expected. This might have been influence by the aspect ratio (i.e. the overall size of the building dimension) of the structural system. This contributes immensely to resistance offered by the structural members to the system. In practice, it has been found useful to have larger plan dimension which aid in improving the rigidity and stability of the building.

Table 4.1: Flexural Rigidity of Structural Members of the Building Model

\begin{tabular}{cccc}
\hline $\begin{array}{c}\text { Structural } \\
\text { Member }\end{array}$ & $\begin{array}{c}\text { Moment of inertia of } \\
\text { Member }\end{array}$ & Rigidity of Member & $\begin{array}{c}\text { Sum of Rigidity of } \\
\text { Member }\end{array}$ \\
\hline \multirow{2}{*}{$\begin{array}{c}\text { Shear wall } \\
\text { rigidity }\end{array}$} & $\mathrm{I}_{\mathrm{sw}} ; \mathrm{m}^{4}$ & $\mathrm{~B}_{\mathrm{sw}}^{\prime}, \mathrm{kN} / \mathrm{m}^{2}$ & $\mathrm{~B}_{\mathrm{sw}}, \mathrm{kN} / \mathrm{m}^{2}$ \\
\cline { 2 - 4 } & 41.71631667 & 1309156039 & 78549362325 \\
\hline $\begin{array}{c}\text { Column } \\
\text { rigidity }\end{array}$ & $\mathrm{I}_{\mathrm{col}} ; \mathrm{m}^{4}$ & $\mathrm{~B}_{\mathrm{col}}^{\prime}, \mathrm{kN} / \mathrm{m}^{2}$ & $\mathrm{~B}_{\mathrm{col}}, \mathrm{kN} / \mathrm{m}^{2}$ \\
\cline { 2 - 4 } & 0.0108 & 289170 & 208202400 \\
\hline Beam rigidity & $\mathrm{I}_{\mathrm{b}} ; \mathrm{m}^{4}$ & $\mathrm{~B}_{\mathrm{b}}{ }_{\mathrm{b}}, \mathrm{kN} / \mathrm{m}^{2}$ & $\mathrm{~B}_{\mathrm{b}}, \mathrm{kN} / \mathrm{m}^{2}$ \\
\cline { 2 - 4 } & 0.015820313 & 423588.8672 & 254153320.3 \\
\cline { 2 - 4 } $\begin{array}{c}\text { rigidity of the } \\
\text { Foundation }\end{array}$ & $\mathrm{I}_{\varphi} ; \mathrm{m}^{4}$ & $\mathrm{~B}_{\varphi}, \mathrm{kN} / \mathrm{m}^{2}$ & $\begin{array}{c}\text { Influence coefficient } \\
\text { for Foundation, } \mathrm{k}_{\varphi}\end{array}$ \\
\cline { 2 - 4 } & 708.588 & 460582200 & 0.0373 \\
\cline { 2 - 4 } & $\mathrm{c}_{\varphi}=50000$ & & \\
\hline
\end{tabular}

Table 4.2, shows the column and beam linear stiffness's offered by conglomeration of the frame system due to the individual structural members (columns 's' and beams ' $r$ ') and the corresponding linear characteristics of the rigidity for combined shear walls and frame network, $S_{w c}$ acting as load bearing structural elements. As observed the values of ' $r$ 'and's' are higher at top level compared to the bottom level and the values of the $S_{w c}$, at the lower region are higher compared the top level. Hence, it can be concluded that the frames support the model at the top and provide higher stiffness; as well, the shear-walls support the model at the bottom and provided the requisite stiffness to stabilize the system. This transpire due the wall-frame interaction (top flexibility, which behaves as a flexural cantilever), as the shear-walls restraining the model in the lower region, and the frames restraining the model in the upper region. Consequently, height is a major factor at determining the influence of the frame on the lateral stiffness of the wall-frame building interaction which is consistent with the findings of [5] \& [6]. 
Table 4.2: Model Linear Stiffness, Structural characteristics and Rigidity

\begin{tabular}{|c|c|c|c|c|c|}
\hline $\begin{array}{l}\text { Height } \\
\mathrm{H}(\mathrm{m}) \\
\end{array}$ & $\begin{array}{c}\text { Column Stiffness } \\
\mathrm{s}(\mathrm{KN} / \mathrm{m})\end{array}$ & $\begin{array}{c}\text { Beam Stiffness } \\
\mathrm{r}(\mathrm{KN} / \mathrm{m})\end{array}$ & $\begin{array}{c}\text { Horizontal Force } \\
\mathrm{F}_{\text {hor }}(\mathrm{KN}) \\
\end{array}$ & $\begin{array}{l}\text { Structural Characteristics } \\
\mathrm{S}_{\mathrm{wc}}\left(\mathrm{KN} / \mathrm{m}^{2}\right) \\
\end{array}$ & $\begin{array}{c}\text { Structural Rigidity } \\
\lambda \\
\end{array}$ \\
\hline 60 & 69400800.000 & 62496718.110 & 131536128.847 & 21.684 & 2.767 \\
\hline 57 & 65930760.000 & 59371882.204 & 124959322.405 & 22.247 & 2.562 \\
\hline 54 & 62460720.000 & 56247046.299 & 118382515.963 & 22.857 & 2.363 \\
\hline 51 & 58990680.000 & 53122210.393 & 111805709.520 & 23.519 & 2.168 \\
\hline 48 & 55520640.000 & 49997374.488 & 105228903.078 & 24.243 & 1.980 \\
\hline 45 & 52050600.000 & 46872538.582 & 98652096.636 & 25.038 & 1.797 \\
\hline 42 & 48580560.000 & 43747702.677 & 92075290.193 & 25.917 & 1.621 \\
\hline 39 & 45110520.000 & 40622866.771 & 85498483.751 & 26.896 & 1.450 \\
\hline 36 & 41640480.000 & 37498030.866 & 78921677.308 & 27.994 & 1.286 \\
\hline 33 & 38170440.000 & 34373194.960 & 72344870.866 & 29.239 & 1.129 \\
\hline 30 & 34700400.000 & 31248359.055 & 65768064.424 & 30.666 & 0.978 \\
\hline 27 & 31230360.000 & 28123523.149 & 59191257.981 & 32.324 & 0.835 \\
\hline 24 & 27760320.000 & 24998687.244 & 52614451.539 & 34.285 & 0.700 \\
\hline 21 & 24290280.000 & 21873851.338 & 46037645.097 & 36.652 & 0.573 \\
\hline 18 & 20820240.000 & 18749015.433 & 39460838.654 & 39.589 & 0.455 \\
\hline 15 & 17350200.000 & 15624179.527 & 32884032.212 & 43.368 & 0.346 \\
\hline 12 & 13880160.000 & 12499343.622 & 26307225.769 & 48.487 & 0.247 \\
\hline 9 & 10410120.000 & 9374507.716 & 19730419.327 & 55.987 & 0.161 \\
\hline 6 & 6940080.000 & 6249671.811 & 13153612.885 & 68.570 & 0.088 \\
\hline 3 & 3470040.000 & 3124835.905 & 6576806.442 & 96.973 & 0.031 \\
\hline 0 & 0 & 0 & 0 & 0 & 0 \\
\hline
\end{tabular}

\subsection{Model Structural Characteristics}

The values of the model structural characteristic, $\mathrm{S}_{\text {wo }}$ at various story level are presented in Table 4.2. As expected, when a multi-storey building is disturbed by wind loading, a unit elastic horizontal displacement (i.e. elastic line) produced will cause a horizontal force equal to $F_{\text {hor }}(\mathrm{kN})$. The larger values of $F_{\text {hor }}$ toward the top of the structure are due to aerodynamic action experience by the structure which is a function of the frame stiffness's at the various levels. This is accordingly, conforming to the established pattern of wind load profile [11].

Figures (4.1 and 4.2) presents values of the characteristics of the structure's influence functions, which are ' $\chi$ ' for only super structure, $\lambda$ for the frame rigidity, influence function coefficient $\beta_{1}$ and $\beta_{2}$. These parameters are critically influenced by the flexural rigidity of such systems and depend on structural characteristics such as stiffness, mass and the overall height of the structural system due to the member sizes and interaction of the system. The corresponding influence function, $\chi$ indicated values of the coordinate at the bottom of the structure asymptotic to unity $(\chi=1$ at the base) and increase exponentially toward the top of the building ( $\chi=2.870$ at the top). The structural characteristics of rigidity $\lambda$ of the multi-story building; shows direct proportionality to the building height and gives a larger value at the top level $(\lambda \approx 2.767)$. This shows that $\lambda$ is influence by the rigidity offered by the frame network in providing the needed resistance on the structural frame. Consequently, at the top of the structure the combined action of the network of frame and shear wall offered the most anticipated resistance. In addition, the value of $\beta_{2}$ has more influence on $\lambda$, than the $\beta_{1}$ and therefore implies that the value of $\beta_{2}$ is more significant to the rigidity of the system. From this it is concluded that the rigidity of the frame and shear-wall interaction is directly proportional or dependent on the hyperbolic tangent of the model height but inversely dependent or proportional to the linear characteristic of rigidity $\left(\mathrm{S}_{\mathrm{wwc}}\right)$.

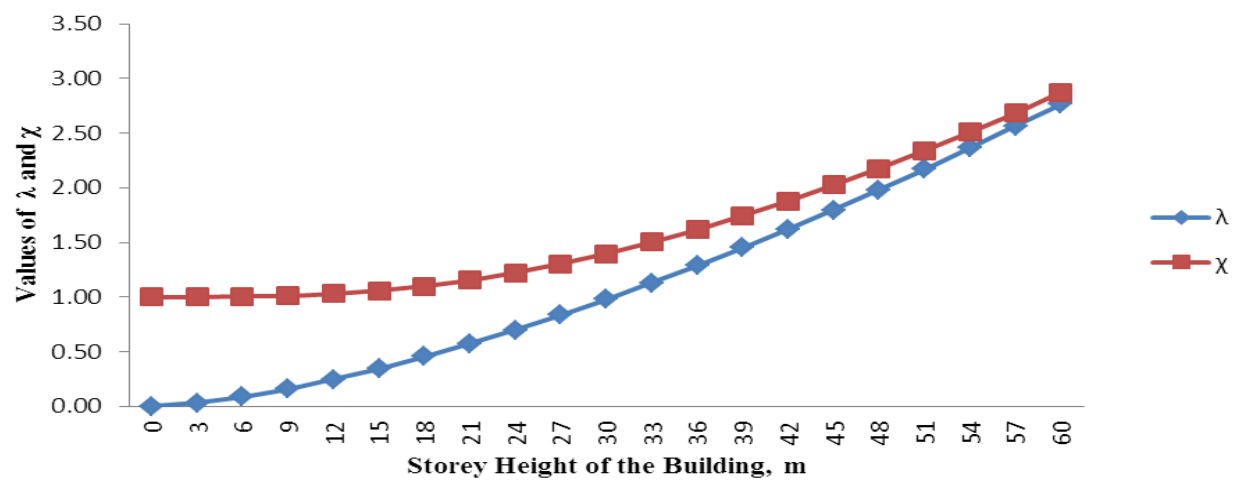

Figure 4.1:Characteristics of Structure's Influence Function on rigidity 


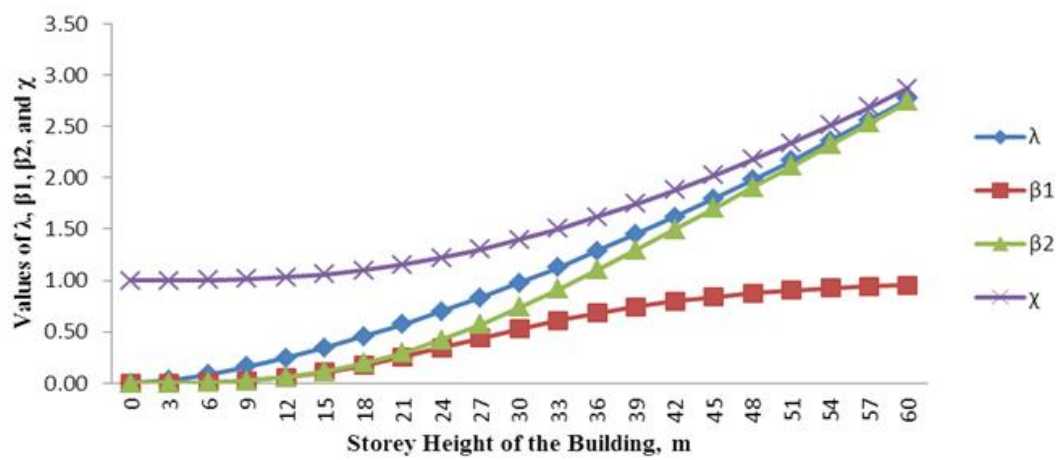

Figure 4.2: Characteristics of Structure's Influence Function on rigidity

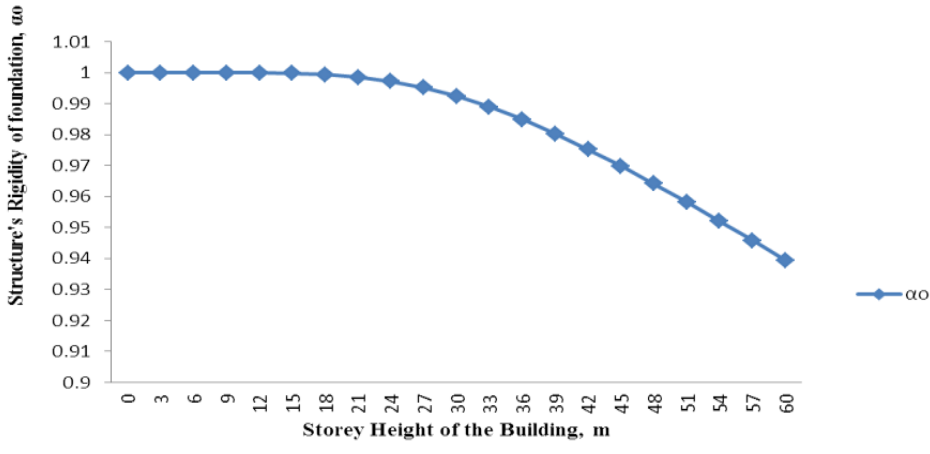

Figure 4.3: Characteristic Influence Function of Foundation Rigidity

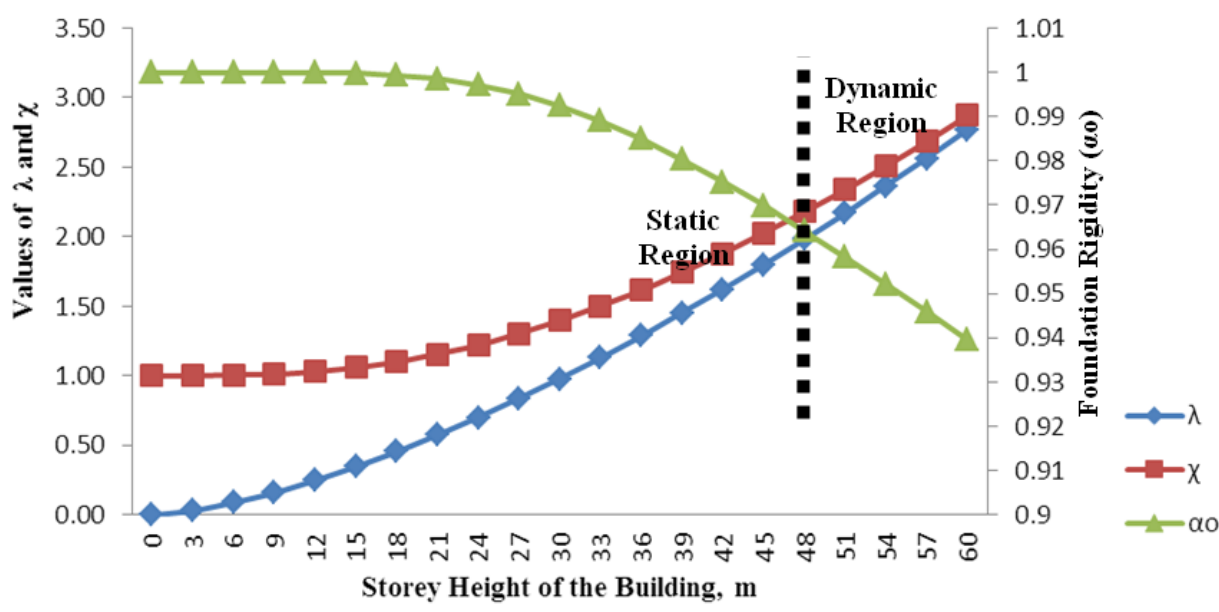

Figure 4.4:Structure's Influence Function on rigidity and Foundation

Figures 4.3 shows the structural characteristics of rigidity for the foundation $\alpha_{0 x}$ as observed the values are asymptotic unity at base $\left(\alpha_{0}=1\right.$, foundation level) and decrease with polynomial and power laws toward the top of the building. This confirmed the large flexural rigidity at the base of the cantilevered system which further indicates the rigidity offered by the foundation base as anticipated of multi-storey building. Moreover the values are influence by the shear wall sub and super structural influence coefficient, ( $K_{\emptyset}=0.037$ ) which assures the rigidity provided by the foundation and its dependence on nature of soil (bed function for the foundation) which is usually a very large value.

It is also observed from Figure 4.4 that the values of the parameters Structure's Influence function on rigidity and foundation, (i.e. influence function $(\chi)$ for only super structure, the characteristics of rigidity $(\lambda)$ of the building and structural characteristics of rigidity $\left(\alpha_{\sigma}\right)$ for the foundation) illustrate an interaction of the shear wall and frame network at the sub and super structure. Accordingly, they were generally increasing and decreasing with polynomial and power laws respectively. The result has shown that, at $(\lambda \approx 1.980$ at the 
intersection corresponding to $16^{\text {th }}$ storey) the structure remains static. Beyond this point, confirms the gradual transition of the modelled building from a static condition at the base to becoming more dynamic at top levels. For this study the building ratio $\mathrm{h} / \mathrm{d}=4.92<5$ but the model period of $\mathrm{T} \approx 1.56 \mathrm{sec}$ with fundamental frequency $\mathrm{f}=0.641 \mathrm{~Hz}$ which further confirms the gradual transition to dynamic response at the top; since building whose fundamental frequency is greater than or equal to $1 \mathrm{~Hz}$ (natural period greater than $1 \mathrm{sec}$ ) are regarded as rigid as reported by [6] \& [3]. This is obvious, because the model like most multi-storey building is more flexible at the top where higher level of wind pressure could be encountered with the building typically less rigid. If the $\mathrm{h} / \mathrm{d}$ $>5$ the point of inflexion for the transition from static to dynamic would have been lower than the $48 \mathrm{~m}\left(16^{\text {th }}\right.$ storey) from the base.

\subsection{Lateral Displacements:}

The lateral displacement increases rapidly from the first storey to about one-thirds of the building height from where the increase with height begins to reduce. The average slope of the curve within the first onethirds of the building height has a sensitive concavity compared to that of the software. Consequently, this as a result the proposed method have the inherent ability to incorporate the infinitesimal foundation rotation in the computational process; accordingly, the result was in compliance as they converged to closer point with a negligible percentage difference of $0.729 \%$ as presented in Figure 4.9. The relationship between building height and lateral displacement is almost linear with a steep slope. The result indicates compliance as expected of multi-storey building subjected to wind load with larger lateral displacement at top story level $\left(f_{\max }=\right.$ $111.51 \mathrm{~mm}$ ). In addition, due to the interaction, the deflected shape of the structure has a flexural profile in the lower part and a shear profile in the upper part as reported by [5].

Check for Allowable Deflection

Maximum deflection against wind allowed is given as

$\frac{f_{m a x}}{H} \leq \frac{1}{500} \quad$ (i.e. $\left.\mathrm{H} / 500\right)$

$\mathrm{H}=60 \mathrm{~m}$

$\mathrm{H} / 500=60 / 500=0.12=120 \mathrm{~mm}$

Therefore

$\mathrm{f}_{\max }=111.51 \mathrm{~mm}<\mathrm{H} / 500$

Accordingly, the minimum limiting condition is satisfied as established. The research result shows that the serviceability criteria is satisfied by the limit $\mathrm{H} / 500\left(\frac{f_{\max }}{H} \leq \frac{1}{500}\right)$.

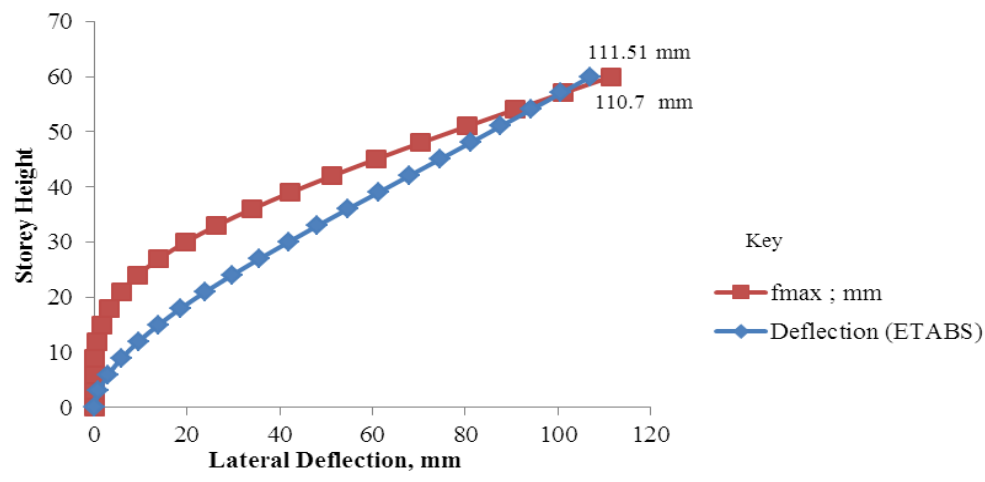

Figure 4.9:Iimproved and Etabs computed Defelection for the Model

\subsection{Inter-Storey Drift of the Building Model (Drift index)}

Wind loading standards and design codes limit the allowable wind drift of the buildings in order to prevent damage to the cladding, partition and interior finishes, to reduce effect of motion perceptibility and to limit the P-Delta or secondary loading effects [1]. Moreover, the inter-storey drift is one of the simple parameter that can be used to estimate the lateral stiffness of a building. Therefore, drift limit is checked for $60 \mathrm{~m}$ tall building in order to determine whether the buildings would exceed the drift index limit or not. As observed in Table 4.3, the inter-storey drift index for both the improved method and ETABS package are in satisfactory accord and are within the limiting maximum standard of 0.005 ranges. The maximum values for the stories located within the middle third of the building height. Consequently, the peak inter-storey drifts for the building occur at the $11^{\text {th }}(33 \mathrm{~m})$ to the $19^{\text {th }}(57 \mathrm{~m})$ storey for the 20-storey building model. Consequently, for this study the results were observed to be within the limit recommended, with 0.002174 as peak at the $13^{\text {th }}$ storey level [12]. And the design drift index limits that have been used on different countries range from 0.001 to 0.005 as reported by [5], [6] \& [5]. 
The minimum required flexural rigidity $\mathrm{B}_{\mathrm{c}}$, of a cantilevered shear wall corresponding to the horizontal displacement $\mathrm{f}_{\mathrm{sw}}$, when the load is resisted by only the shear wall action was presented in Table 4.4. As expected the shear wall offered the minimum requisite rigidity to resist the aerodynamic loading.

Table 4.3: Inter-storey Drifts of the Model

\begin{tabular}{|c|c|c|c|}
\hline Storey & $\mathrm{H}(\mathrm{m})$ & ETABS & Improved Method $\frac{-\pi-4 B}{i n}$ \\
\hline$\overline{60}$ & & 0.00204 & 0.00350 \\
\hline 57 & & 0.00206 & 0.00346 \\
\hline 54 & & 0.00209 & 0.00340 \\
\hline 51 & & 0.00211 & 0.00334 \\
\hline 48 & & 0.00214 & 0.00325 \\
\hline 45 & & 0.00216 & 0.00313 \\
\hline 42 & & 0.00217 & 0.00297 \\
\hline 39 & & 0.00217 & 0.00278 \\
\hline 36 & & 0.00216 & 0.00253 \\
\hline 33 & & 0.00214 & 0.00224 \\
\hline 30 & & 0.0021 & 0.00191 \\
\hline 27 & & 0.00203 & 0.00155 \\
\hline 24 & & 0.00195 & 0.00118 \\
\hline 21 & & 0.00183 & 0.00084 \\
\hline 18 & & 0.00169 & 0.00055 \\
\hline 15 & & 0.00152 & 0.00032 \\
\hline 12 & & 0.0013 & 0.00016 \\
\hline 9 & & 0.00105 & 0.00006 \\
\hline 6 & & 0.00074 & 0.00001 \\
\hline 3 & & 0.00042 & 0.00000 \\
\hline 0 & & 0 & 0 \\
\hline
\end{tabular}

\subsection{Stability of Multi storey Building}

The stability of the building is evaluated by checking of storey drifts, and lateral displacements which is observed to be ensured by the appropriate flexural rigidity provided by the system (Structural elements). The details of the analysis results from ETABS package were presented in the appendices 1, and it can be deduced that the proposed method is in compliance with the results.

\subsection{Preliminary Size Determination}

Depending on the percentage of reinforcement required, the required area of concrete column may be determined by equation [13]:

$$
\begin{aligned}
& A_{C}=\frac{3 N}{f_{0 K}} \text { for } \mathbb{N} \leq 1000 \mathrm{KN} \\
& A_{\mathbb{C}}=\frac{225 \mathrm{~N}}{f_{0 \mathrm{~K}}} \text { for } \mathbb{N}>1000 \mathrm{KN}
\end{aligned}
$$

where; $\mathrm{N}$ is Axial Load and $\mathrm{f}_{\mathrm{ck}}$ is characteristic strength of the concrete.

Overall depth of beams: This depend on the member span/overall depth ratio, for a rectangular beam the minimum depth, $\mathrm{h}>250 \mathrm{~mm}$ or $\frac{\mathrm{L}}{15}$. For a more appropriate sizing of concrete beams in millimeters are to be determined by:

$h_{b}=1.45 \sqrt{\frac{M_{0}}{b f_{0 k}}}$

where; $\mathrm{M}_{\mathrm{o}}$ is the bending moment at the beam joint for wind or seismic loadings and the width to be guided $b \geq \frac{L}{60}$ is the concrete web, $\mathrm{L}$ is the beam effective span and $\mathrm{f}_{\mathrm{ck}}$ characteristic strength of the concrete.

For a shear wall with solid rectangular cross section subjected to aerodynamic loading, the wall thickness as a cantilever due to uniform load is given by:

$t=\frac{\text { wo } n d}{E}\left[\left(\frac{H}{L}\right)^{3}+\frac{H}{L}\right]$

where; $w$ is uniform lateral load, $\mathrm{H}$ is the height of the wall, $\mathrm{E}$ is modulus of elasticity of the wall material, $\mathrm{L}$ is length of wall, $t$ is the minimum thickness of the shear wall, and $n_{d}$ is a number that depend on the minimum deflection limit adopted (for the recommended value of deflection limit H/500, $\mathrm{n}_{\mathrm{d}}=750$ ). The implication of this is that for more stringent value of deflection limit, $\mathrm{n}_{\mathrm{d}}$ also increases to higher values and vice versa. For this study $t=175 \mathrm{~mm}$ thick shear wall was adopted. In view of that, this provides a basis for preliminary member sizing at the early stage of the analysis which would results in a rapid convergence of the iterative process to the desired design solution. 


\section{Concluding Remark}

The maximum deflection along the building, $\mathrm{f}_{\max }$ of the approximate improved method have the inherent ability to incorporate the infinitesimal foundation rotation in the computational process; accordingly, providing a solution to one of the challenges of high rise buildings in terms of stability. the result was in satisfactory accord as they converged to closer value with a negligible percentage difference of $0.729 \%$, that satisfies limiting serviceability requirements.

Therefore, in designing tall buildings subjected to aerodynamic wind excitation, the rigidity and robustness of the structural members are significant not only to ensuring the stability of the system but also of the comfort of the occupants since motion perception level were moderated.

\section{Reference}

[1] Mendis, P., No T., Haritos N., Hira A., Samali B. and Cheung, J. (2007). Wind Loading on Tall Buildings. EJSE Special Issue: Loading on Structures.1-14

[2] Snæbjörnsson J. T. (2002). Full and Model Scale Study of Wind effect on a Medium-rise Building in Built up Area. University of Norway, Department of Structural Engineering, Doctoral Thesis.

[3] Onundi, O. L. (2010). The Impact of Climate Change on Sustainable Infrastructural Development a Case Study of the Appropriate Wind Speed and Other Measures Required for Design of Tall Structures in Nigeria. Proceedings the $19^{\text {th }}$ Engineering Assembly of the Council for Regulation of Engineering in Nigeria (COREN).19(1):146 - 166.

[4] Jayachandran, P. (2009). Design of Tall Buildings Preliminary Design and Optimization. National Workshop on High-rise and Tall Buildings. University of Hyderabad, (jayachan@wpi.edu) Hyderabad, India

[5] Smith, B. Stafford and Coull, Alex. (1991). Tall Building Structures: Analysis and Design. A Wiley inter-science publications John Wiley and Sons Inc. New York.

[6] Taranath, B. S. (2010). Reinforced concrete Design of Tall Buildings. CRC Press Tylor and Francis group, LLC, pp 325-333

[7] Pavani, M., Kumar, G. Nagesh and Sandeep, Pingale. (2015). Shear Wall Analysis and Design Optimization in Case of High Rise Buildings Using ETABS software. International Journal of Scientific \& Engineering Research, Volume 6, Issue 1, January-2015 546, ISSN 2229-5518. IJSER @ 2015 http://www.ijser.org

[8] Chen, W. and Lui, E. M. (2006). Principles of Structural Design. CRC Press Taylor \& Francis Group, London

[9] Park, H. S., Hong, K. and Seo, J. (2002). Drift Design of Steel-Frame Shear-Wall Systems for Tall Buildings. The Structural Design of Tall Buildings, Vol. 11, No. 1, 2002, pp. 35-49.

[10] Nisimov, H. (1984). Ctomano-Betonni Ckelettni Konstrukti 3a Monogo Estashni Cgradi. Unity press (Technical).1st Ed., Sofia. pp. $(141-171)$

[11] Nisimov, D.C. (1984). Stomano-Betonni Skelettni Konstruktsi za Monogo Etaghzni Cgradi. C/o Jusautor. Unity Press, Technical Sofia, pp 325-333.

[12] CEN-European Committee for Standardisation (2005). EN 1991-1-4: Actions on structures. General actions. Wind actions. European Standard Brussels: CEN 2005.

[13] ETABS Version 2015 (2015). Extended 3-D analysis of the Building Systems. California, Computers and Structures Inc., Berkeley.

[14] Onundi LO, Matawal D.S and Elinwa, A.U. (2010). The Influence of Euler Critical Load on the Method of Initial Parameters for the Dynamic Analysis of a Multi-storey Building Subjected to Aerodynamic Forces.

[15] Onundi L.O., Suleiman B. and Amodu (2015)', An Approximate Method for The Analysis of Rigid Framed Medium Rise Building subjected to Aerodynamic Loadings" M. F. Continental J. Engineering Sciences 10 (1): 9 - 26, 2015 ISSN: 2141 - 4068 Wilolud Journals, 2015 http://www.wiloludjournal.com Printed in Nigeria doi:10.5707/cjengsci.2015.10.1.9.26

[16] Onundi LO, Matawal D.S and Elinwa, A.U. (2010). The Influence of Euler Critical Load on the Method of Initial Parameters for the Dynamic Analysis of a Multi-storey Building Subjected to Aerodynamic Forces. Continental J. Eng. Sci., 5:1-13, 2010 ISSN: 2141-4068. http://www.wiloludjournal.com 